
Doganapat, dndiama
Geme 2-5, 1964 


Washingtol to angola, elnd.
enittisl mileage 330 .

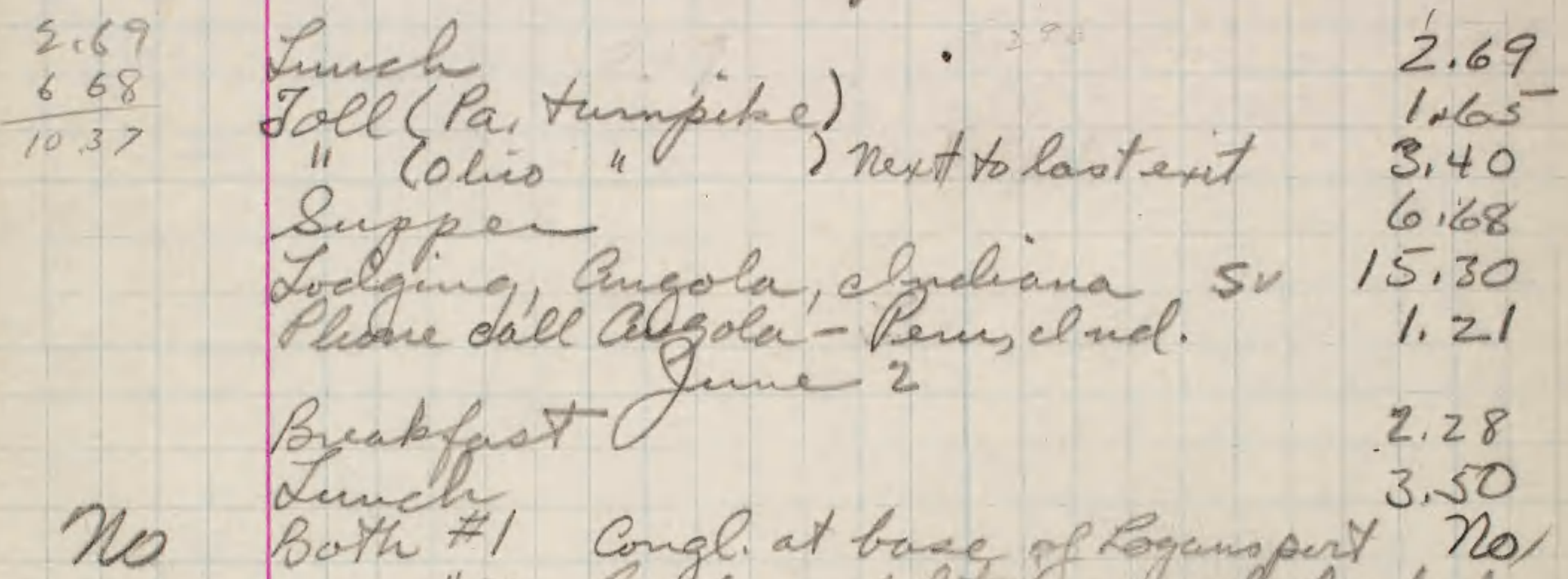

No Both \#1 Congliat base of Brampert No bw $+7-9$ Sfingo

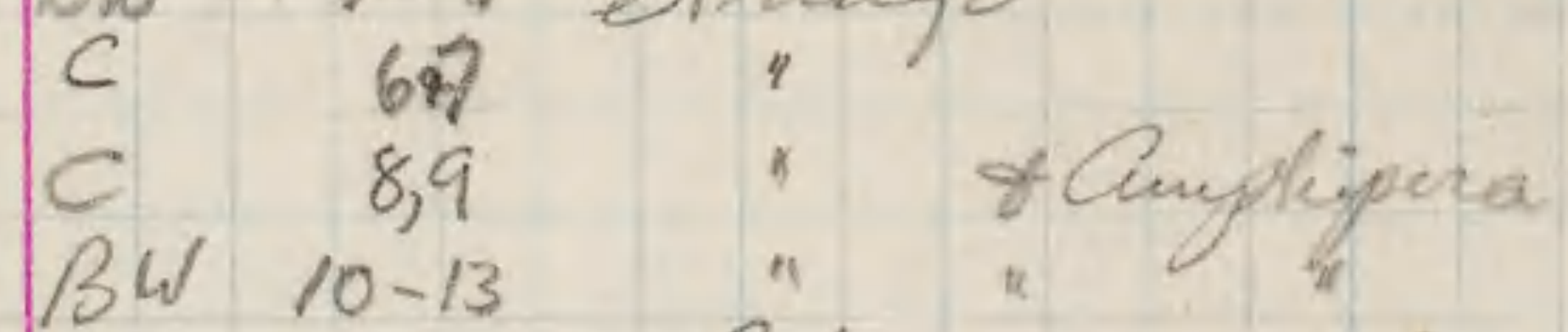

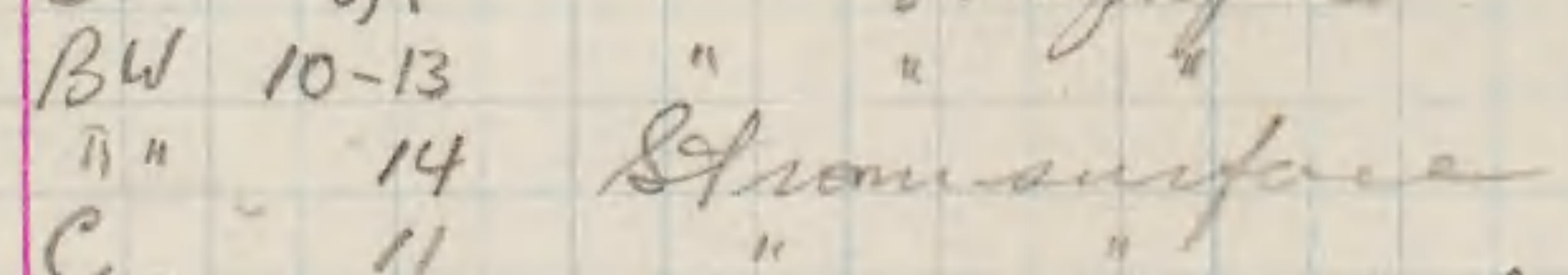

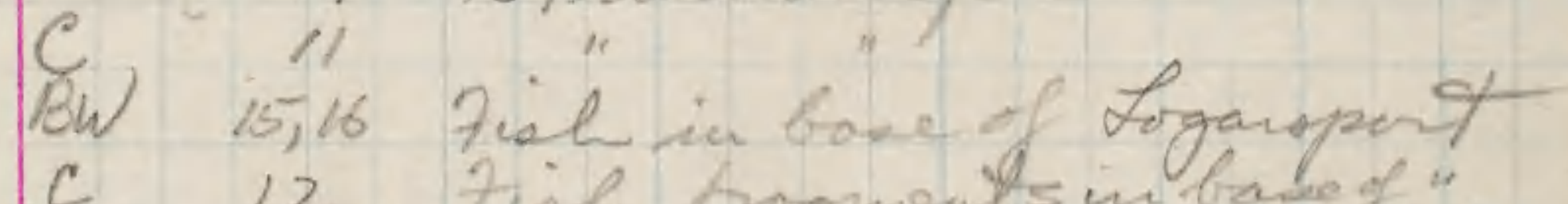

C 12 7ish frogmants inbang".

BW17-19 Southwall showing sil, Stang of Longawo 6.31

c $14-16$

Penselardia erlected fune 2

trom NE an.SEI/4 SE/4 28-27N-2E

0.3 miles Son Pattawatamie Boint ed

of 48,24 and $a b$ nt $100^{\prime}$ wery

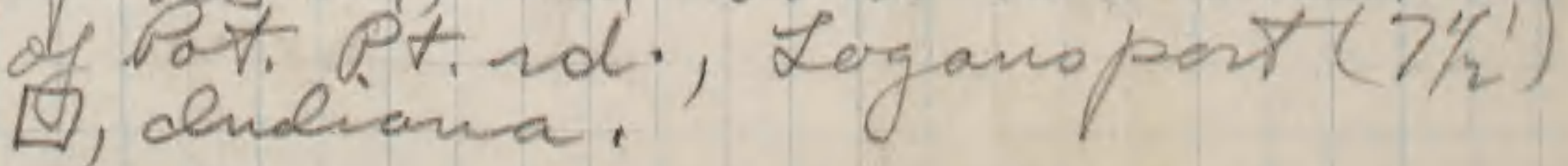




\section{Sene 2}

Westside tavice stoxe ay aboutconter NEI/4 Z7-27N-ZE, Logarepof $(1 / 2) \square$ Fibly in showting slight salief (6") where confact was peene. Ton recunds st feet of so ot bao a but not entiluen. Lines tone light

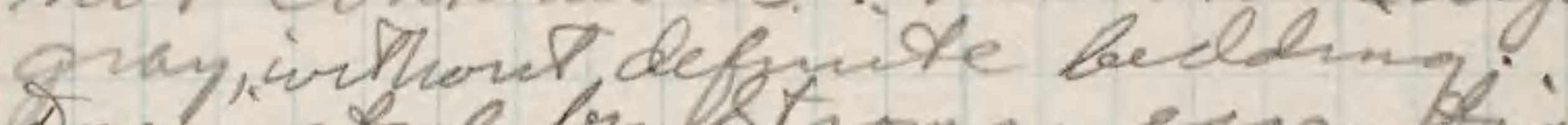
Doncmat of by rome. exsenfiach. a cange. of theng. Cuabnat weel

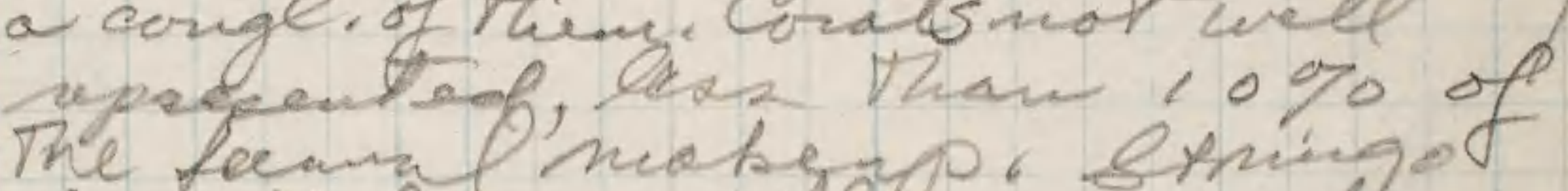
The fawal nobepo. bringot in patchos math on surpoce

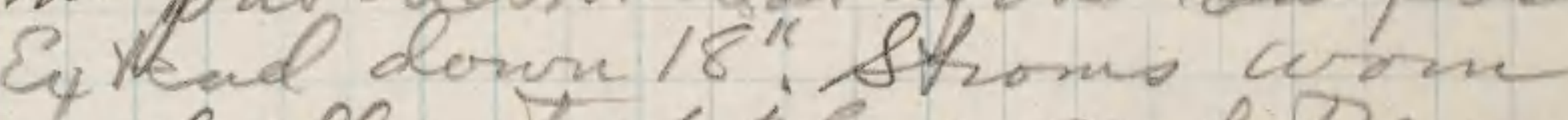
and aflont of place and the vast majovity at lam angle of up rede upside down. One trine ite la averlain by Logavopert $e_{s}$

on sowth wall of quany Siar lo io obular lof 14' If Logan pert, thongly

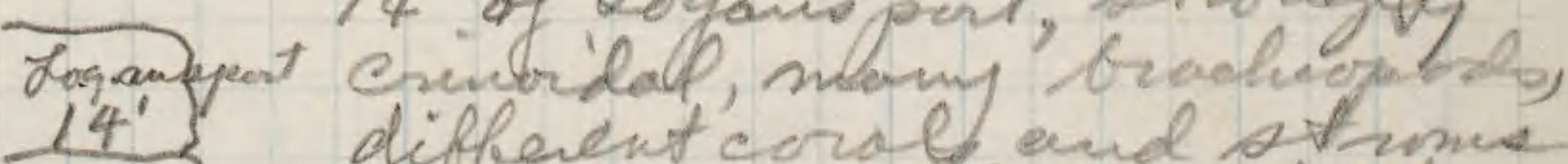
sting differenterial and strmes II' with eonugated base

sil June 3

Breakfast with Phelano 


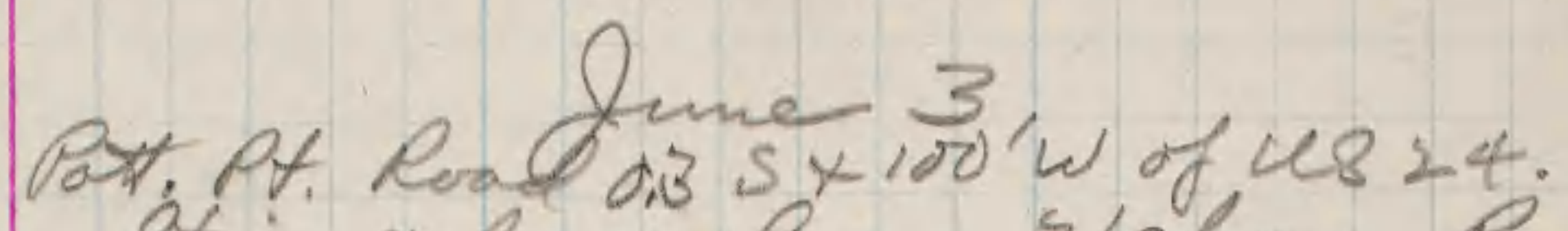

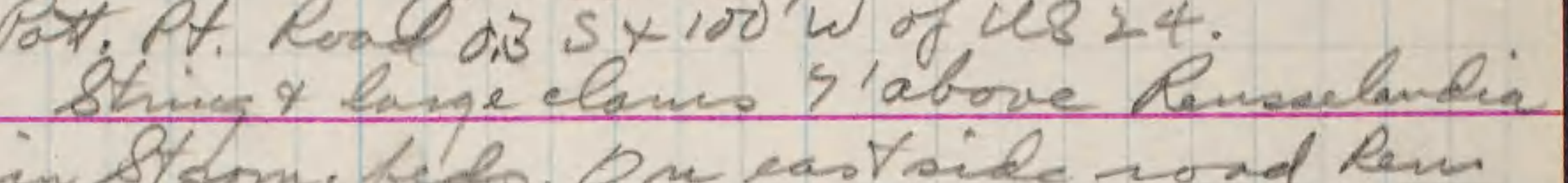
in Sthm; beb. On castside rond lew Congh. On NW mast prod hill coving 7 tapere. Sechon is anly Sonth side 5 henob \&32

1) Cirals and 8 troms. anseth shoms

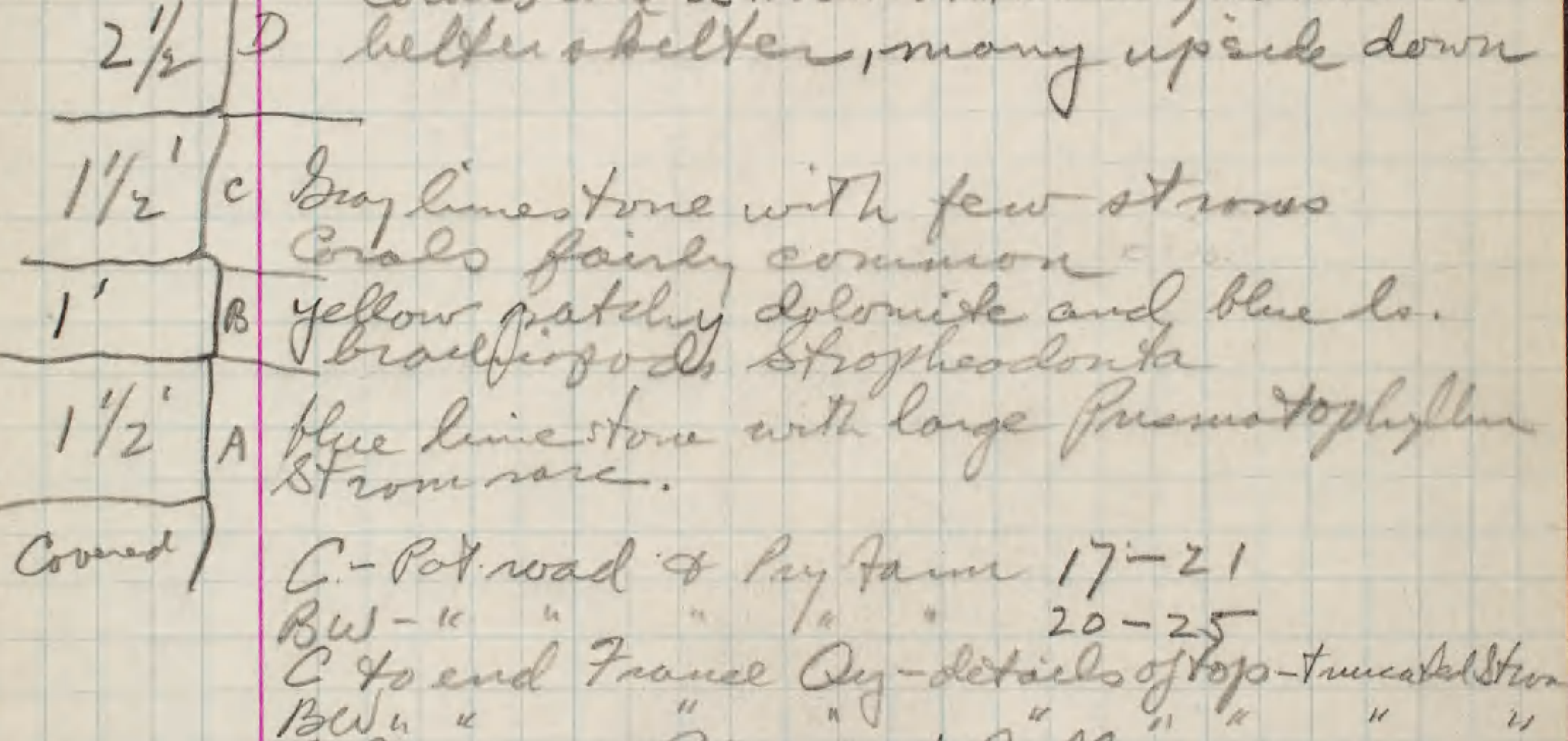
"Color "0-3 Pipe "reek tolls"

BW I " " " atbiedge

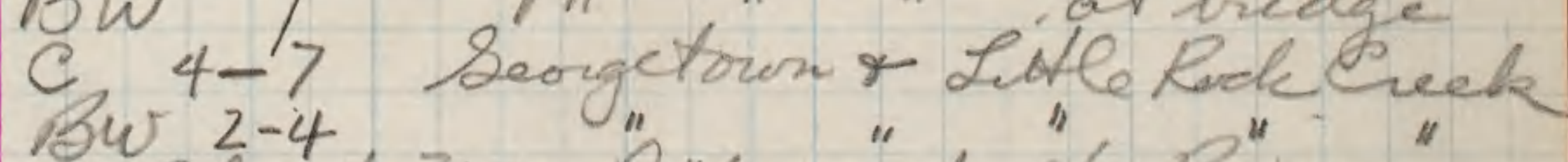
Cboit 3:30 PM weit "to Pues crete fafls - ow gray beel

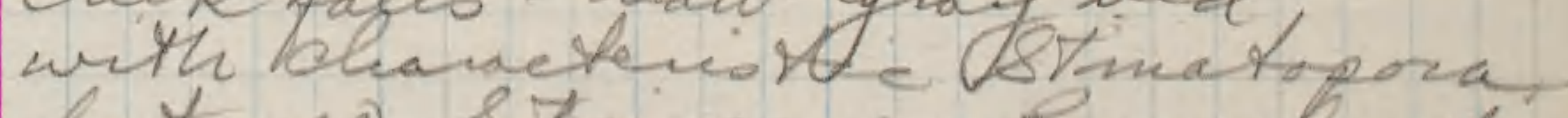
but no \&tringo or kenwala dea 
Sective west side Trane Qy

$10^{\prime}$ String ocoploblus in top $11 / 2$ fect. cucley becleded to helfer she ot en enals and Stroms, the latter predominant Whegartropdia at base $=7 \mathrm{~m}$ 7am ${ }^{-}$cardy es, sandgrains frosted Silurian Nobeno dal wifh small
brach. Cavities 9 Halgnites Two patches of string o- the

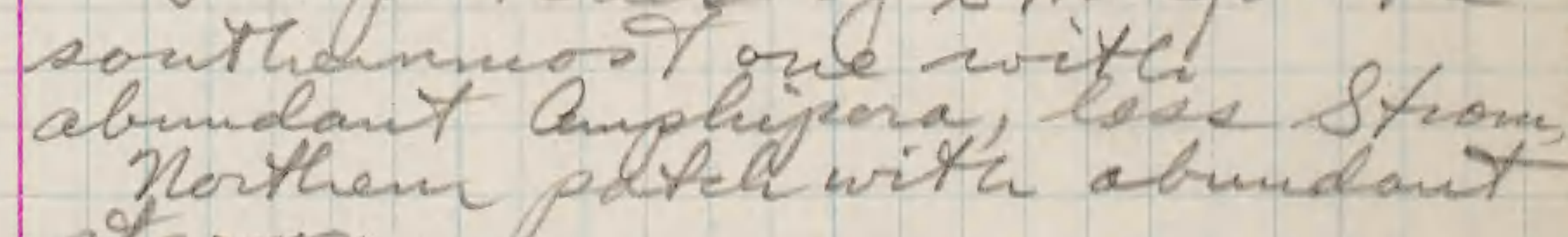
plowthen plete with abundant

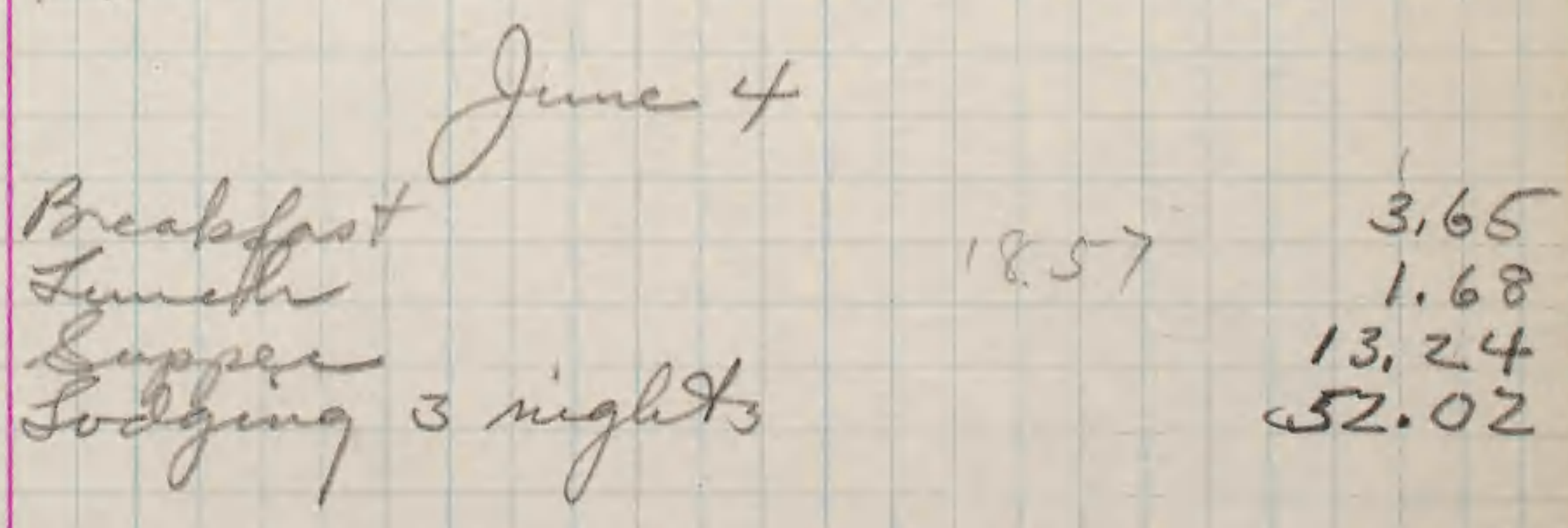




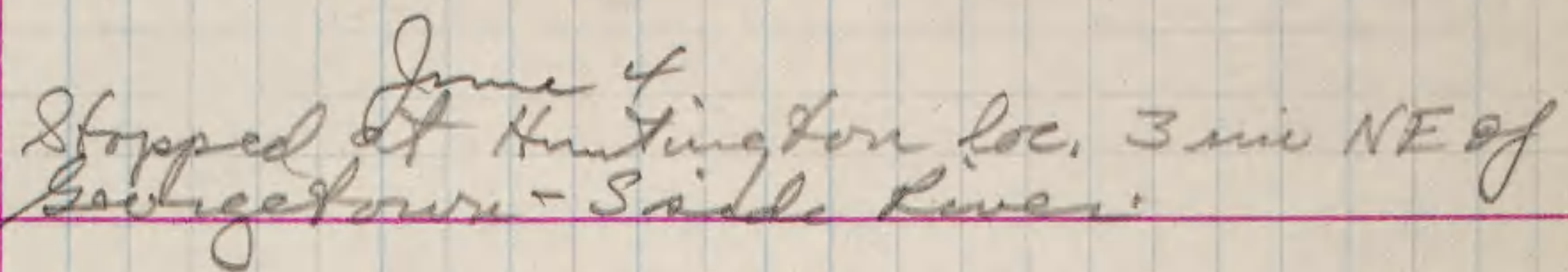
Wert of findge abmit 100-150 jd.

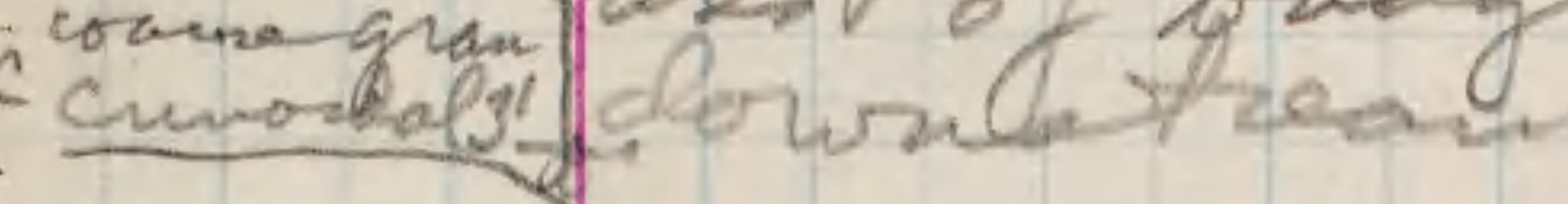

5 ' 3 Thine be lded fina gramed

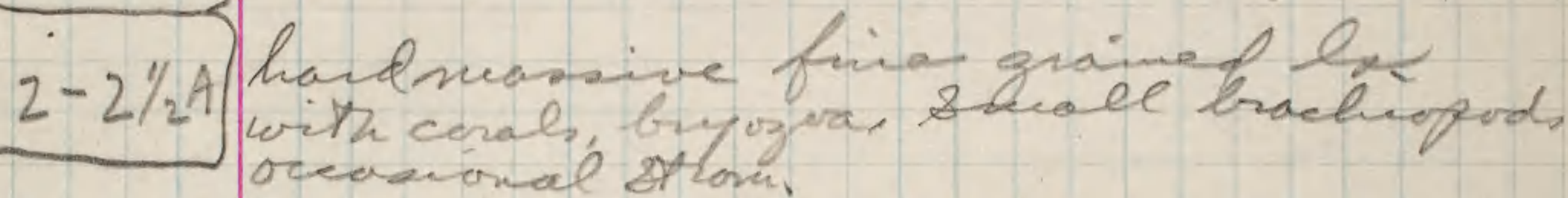

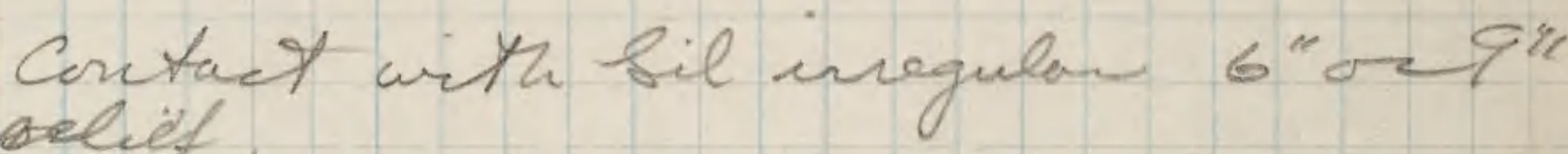
selif.

C- formo Thin slain on top of $B$ G"11 but some in fild on stide soad Thi locality is 300 paces west of the bibeg. 750', at a omall batural birdge showing contact of Silvian ald Devomant.

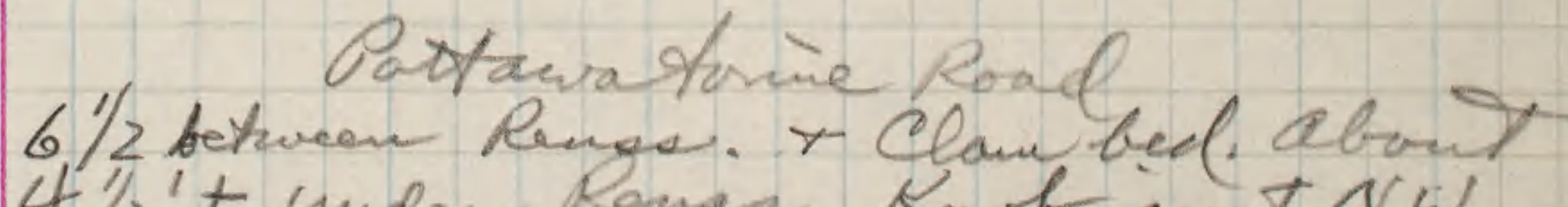
$41 / 2$ 't under Ranies. Enob juot NW of the west holf. mosth joganopost 


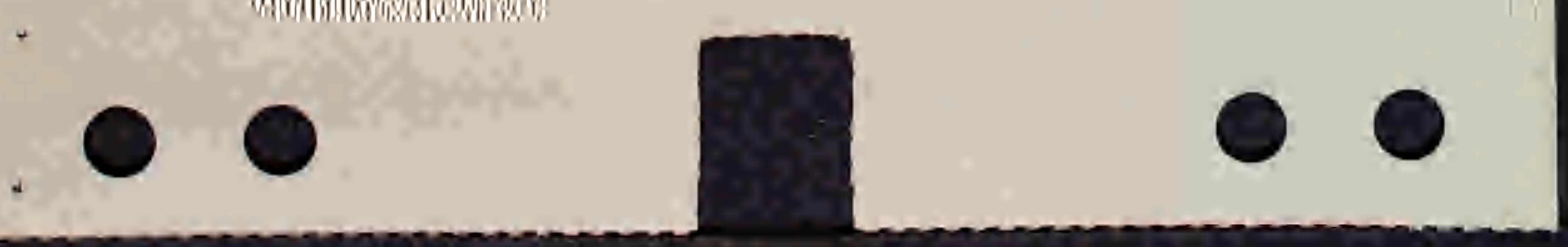


Left Leganlopert 5 > 30 A m. at 1155

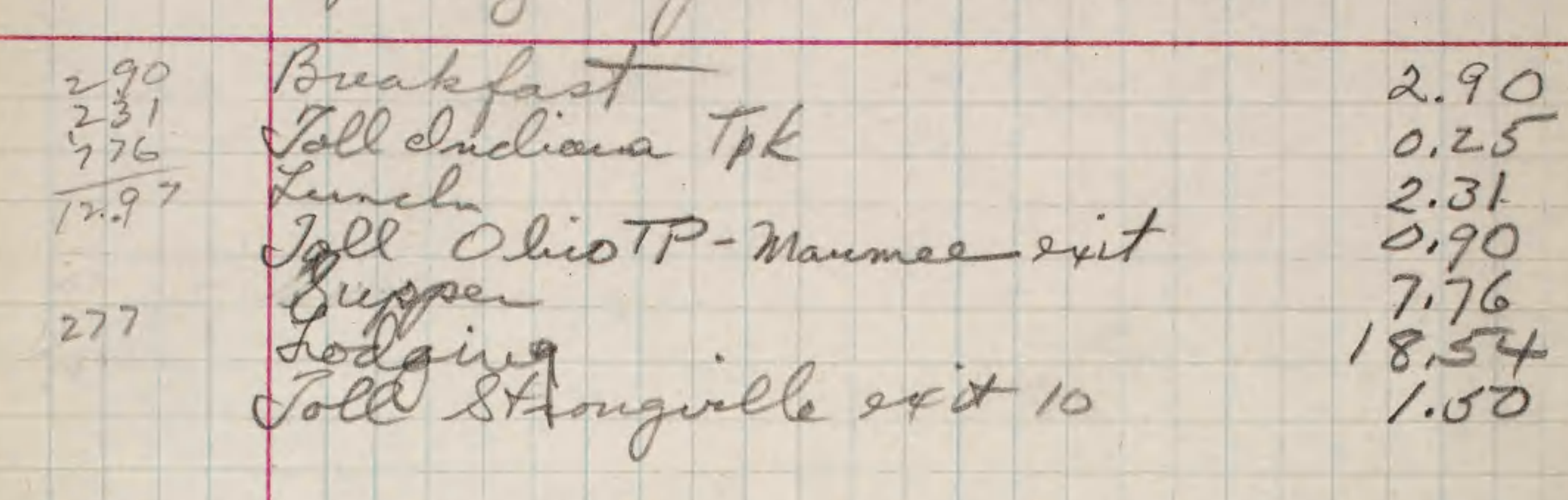

Visited Quany sw of Sylvania ton a few homs. Went to Nendi spinf The c.conena tus bed ithich is 3'thide

659 Brealefant fune 5

olisto. Foll

2.77

pinch tole

$1.2 \Delta$

3,85 